\title{
Promoting Remanufacturing through Collaboration
}

\author{
Iris Karvonen, Kim Jansson, and Mikko Uoti \\ VTT, P.O. Box 1000, 02044 VTT, Finland \\ \{Iris.Karvonen, Kim. Jansson, Mikko.Uoti\}@vtt.fi
}

\begin{abstract}
Remanufacturing is an ultimate form of recycling by manufacturing "good as new" products from used products. Through remanufacturing, materials and energy can be saved and less waste is produced. However, at present, the application of remanufacturing is common only in specific industrial fields and geographic areas. This paper describes challenges identified and discusses how collaboration and networking of companies can support the implementation of remanufacturing. In addition to cases described in literature, the study uses information collected from Finnish case companies operating in remanufacturing.
\end{abstract}

Keywords: remanufacturing, life cycle, collaboration.

\section{Introduction}

Remanufacturing is one form of product end-of-life strategies, often called 6R: reduce, reuse, recycle, recover, redesign, remanufacture [1], aiming for resource efficiency. Remanufacturing can be seen as an ultimate form of recycling: it re-uses more of the assets put in a product or a component than recycling: in recycling large amounts of energy and labor are lost [2]. The idea is not to refit the product or product part for the same user but systematically take back end-of-life goods and re-use them or their components for new users.

There are several definitions for remanufacturing, for example:

"recycling by manufacturing "good as new" products from used products" [3], "the process of restoring a non-functional, discarded, or traded-in product to likenew condition” [4].

Remanufacturing is one form of so called "circular economy", defined as "an industrial system that is restorative or regenerative by intention and design" [2]. Circular economy is not based on consumption but on restorative use. A recent report [2] reviews the potential of circular economy from a European viewpoint and estimates enormous potential for savings at the European level and new innovation potential to realize the circular economy. Thus it can be seen as one path to reindustrialization in Europe.

Remanufacturing has been performed in some form for decades but as an industrial activity it is well known mainly in specific industrial fields and few geographical areas, like photocopier, printer and camera industry in Japan [5], motor vehicle parts, electrical components, industrial machinery and office furniture industry in USA [4] and car industry in Germany [3]. Currently, as the awareness and interest in ecologic 
sustainability is growing, also remanufacturing is achieving more attention. In Europe interest for remanufacturing is highly linked to the European requirements of recycling in car industry. In China remanufacturing is still in the primary stage but there is political pressure to grow in this area [6].

To move from small-scale remanufacturing to industrial remanufacturing, radical rethinking of physical products, their lifecycle and the production and service system as well as the creation of totally new operations and value networks is needed. Chapter 2 presents the background of this paper. Chapters 3-4 describe the benefits and challenges of remanufacturing, both based in literature and commented with the Finnish case company experience. Chapter 5 describes the remanufacturing processes and how collaboration and networking between enterprises could support overcoming some barriers. Chapter 6 gives the conclusions.

\section{Research Context and Approach}

In Finland a research programme "Green Growth" was started by the national research funding organization Tekes in 2011. The aim of the programme is "to identify potential new growth areas for the sustainable economy business, which are essentially based on lower energy consumption and sustainable use of natural resources" [7]. Within this programme, in 2012, project DemaNET was started. DemaNET comes from "Dematerialization and Sustainable Competitiveness through New Models for Industrial Networking". One of the focus areas of the project is remanufacturing. The aim is to study how remanufacturing can best be applied in Finnish industry. The project is participated by ten industrial companies which have interest for sustainability and part of them specifically in the remanufacturing business. The companies are on different application levels. Four of them have currently some commercial remanufacturing activities; one of them just started a new remanufacturing factory for specific product components. In future the companies may also act in different roles: One of them is looking for partners to develop the activity in a specific region; as an SME it is not able to perform remanufacturing alone. One of the companies is a potential service provider for remanufacturing but has no activities and experience yet in this field.

This paper is based on the work carried out in DemaNET during the first year. Previous research about remanufacturing has been studied to identify its benefits, challenges and applications and to analyze the processes and systems applied. The industrial views have been surveyed through semi-structured interviews and workshops with the case companies. The observations from outside Finland and the experience of the companies have been shared and discussed between the participants. Finally in the project the aim is to consider how the remanufacturing concept could be applied in Finnish industry; how the barriers could be overcome and what kind of actions are needed in the long term to promote remanufacturing on a larger scale in industry and economy.

\section{Remanufacturing Benefits}

Within the IMS (Intelligent Manufacturing Systems) a vision and roadmap for sustainable manufacturing has been developed in 2010 [8]. The vision foresees that 
"Successful European enterprises have to adapt to sustainable manufacturing approaches, based on a precise esteem of the whole life-cycle environmental impact." Thus sustainability is seen as a competitive factor for future industries and reindustrialization. The roadmap [8] also recognizes remanufacturing: "The development is going towards an "eternal life-cycle" of products and remanufacturing is becoming more important as many countries are tightening environmental regulations or legislations in economic activities".

Remanufacturing is referred to as a "win-win-win" situation: customers need to pay less for the remanufactured products or components, remanufacturing companies earn more and the environment benefits [9]. As a whole, remanufacturing is expected to contribute to all three dimensions of sustainability (environment, economy, society): Remanufacturing "saves material and energy resources, prevents waste, creates skilled jobs and produces substantial savings over new goods with new components". While looking at remanufacturing from the American perspective also Lund \& Hauser [4] identify several benefits at the level of society: It makes products more broadly available at lower prices, it makes a contribution to conservation of materials and energy and it provides employment income and acquisition of skills and expertise which can lead to additional business opportunities for repair, remanufacture, or manufacture, thus providing local employment and training. Thus through becoming more common remanufacturing can support the reindustrialization.

The case companies involved in DemaNET project also recognized the importance of all the three sustainability dimensions as benefits of remanufacturing. Even if sustainability is often used as a selling argument, the companies regarded that so far only part of their customers are highly interested in sustainability. The main driver of the case companies for remanufacturing is profitable business. Through remanufacturing new markets and customer groups may be reached. As two of the companies apply remanufacturing for spare parts of heavy machines they see remanufacturing also as a method to keep up the spare part market for themselves. Sometimes there is a concern if remanufactured products decrease the sales of new ones. This was not seen relevant in the case companies. On the contrary they saw that remanufacturing may support sales of new products through taking back the used ones; this is seen as a part of the "whole service" to the customers. Remanufacturing also supports the feedback of product experience: information flow from product use to new product design.

\section{Barriers and Challenges}

Even if remanufacturing is widely spread in some limited fields or geographical areas, in other fields it is small scale activity. Partly this is because the raw materials or components are currently not expensive enough, the awareness of remanufacturing is still low and the regulations do not oblige for ultimate recycling. On the other hand, there are also barriers to implement remanufacturing as a profitable business. Matsumoto \& Umeda [5] and Lundmark et al. [9] have identified three main areas of challenges according to the main phases of remanufacturing:

(1) Challenges related to the collection of used products / availability of cores: To establish remanufacturing sufficient volume of cores (used products or components to be remanufactured) need to be available and brought together for remanufacturing. 
Even if there is potential for sufficient core volume in the market area, the remanufacturing companies need to take care that the cores are returned to them.

(2) Challenges related to remanufacturing processes (remanufacturing phase): Not all products or product parts can be remanufactured in a reasonable way. There may be technical challenges, it might be difficult to assure of the required quality, or the costs and lead time are too high. It is often difficult to identify the potential products for which remanufacturing is profitable, technically feasible and really sustainable [10].

(3) Challenges related to the demand for remanufactured products [5] and redistribution [9]. One main challenge of demand is to reach the customers' acceptance and trust in remanufactured products.

A challenge related to all these phases is the difficulty of balancing the supply and demand $[5,9,10,11]$. Remanufacturing companies most often do not have control about the quantity, quality and timing of the returned products.

Additionally, other types of challenges can be identified, related to management and business (for example cost-effectiveness and pricing), legislation and IPR issues.

The challenges identified by the project case companies were mainly in line with the observations in literature. One of the main criteria to start and run profitable remanufacturing is to reach sufficient volume. For part of the companies this could be managed through the selection of proper components or modules for remanufacturing the volume of which is high enough. Because of insufficient volume one of the companies is currently able to perform remanufacturing only in the primary market area. In one SME case, the manufacturer of large and heavy products, the product volume is distributed globally and no region has sufficient volume for remanufacturing. In addition to the mentioned challenges, the companies highlighted the need for local market understanding and knowing the local government regulations (for example sometimes the export of cores may be prohibited). When developing new activities in remanufacturing, the companies also experienced a need for resources and knowledge: technical information and test specifications are needed. Additionally the products should be better designed for reuse and remanufacturing.

\section{$5 \quad$ Remanufacturing Processes and Collaboration}

\subsection{External and Internal Processes}

Remanufacturing processes can be seen as consisting of external and internal processes, figure 1. The external process has two parts: "external in" taking care of the collection and input of cores and "external out" distributing the output of remanufactured products to customers. The figure presents different routes for the external processes; they are not present simultaneously for one product. The remanufacturing internal processes contain the needed manufacturing steps to recondition the incoming cores to the needed quality level. Not all used products qualify for remanufacturing; the pre-check of the cores may be performed in different phases, depending on the case. Storage and transport operations are needed both inside the phases and between them. In figure 1 storage and transport are left out, to keep the description more simple. To perform remanufacturing it is necessary to build up the whole remanufacturing system, not only the actual remanufacturing activities. 


\section{External in Process (Collection of Cores)}

The external in process takes care of the collection of the used products or components (cores) from the customers. As seen in figure 1 there are several options for the core return. Delivery of spare parts or receiving used products when buying new ones, are typical occasions for core collection. Other sources of cores are for example salvage operators and core brokers, rental units returned at the end of lease, and items found defective during an initial warranty period [4]. As mentioned above in chapter 3, the market needs to be high enough to create the collection channels and the reverse logistics system.

The collection of cores needs to be organized easy for the customer and costefficient for the remanufacturer. To support the core availability the remanufacturing companies often create incentives for returning them. They offer cash or deposits of used products or discounts when purchasing new products and returning the used ones. Offering products as a service, leasing or collaboration with leasing companies can support managing the used products or parts and thus may help both to reach sufficient volume and to decrease the supply uncertainty.

\section{Internal Remanufacturing Processes}

The remanufacturing internal processes include the steps for the recondition of the incoming cores to the needed quality level: inspection, cleaning, disassembly, reprocessing, reassembly, testing and storage [3, 12]. Depending on the core, these phases may be performed in a different order.

Not all products are suitable for remanufacturing. Hauser \& Lund [13] identify the following remanufacturing criteria from the product viewpoint: Technology exists to restore the product, product is made up with standard restorable parts, cost of core is low relative to savings in product cost achieved through core reuse and the product technology is stable over more than one lifecycle.

The most cost-efficient and sustainable solution can be achieved if the product is specifically designed for remanufacturing. This means that the products are easy to disassemble and assemble, more durable material is selected, the parts are easy to recover and test and standardized as far as possible. Currently, only few products have been designed for remanufacturing and few designers are aware of design for remanufacturing [14].

\section{External Out Process (Remanufactured Products to Customers)}

There are also several options for the sales and distribution of remanufactured products and components to the market but not all of them are applied simultaneously for one product. Sometimes they are sold through the same channels as new ones (spare parts) but often the market areas or the customers for used and remanufactured products are different from those of new products. In some fields with high volume specific remanufacturing marketplaces are available in the internet. The customer base can be enlarged by identifying proper cores for the remanufacturing (for example spare parts), a credible quality offer (for example longer guarantee than for new parts), lower pricing and financial incentives for the used cores when buying remanufactured products.

One way to stabilize the demand of remanufactured parts is to use them as components in new products. According to Matsumoto \& Umeda [5], in Japan 
remanufactured components are used also in new products in photocopier and camera industry. The advantage is that the timing of supply does not depend on the timing of returns, the customer does not define the reuse ratio and the potential conflict between sales of new and remanufactured products is avoided.

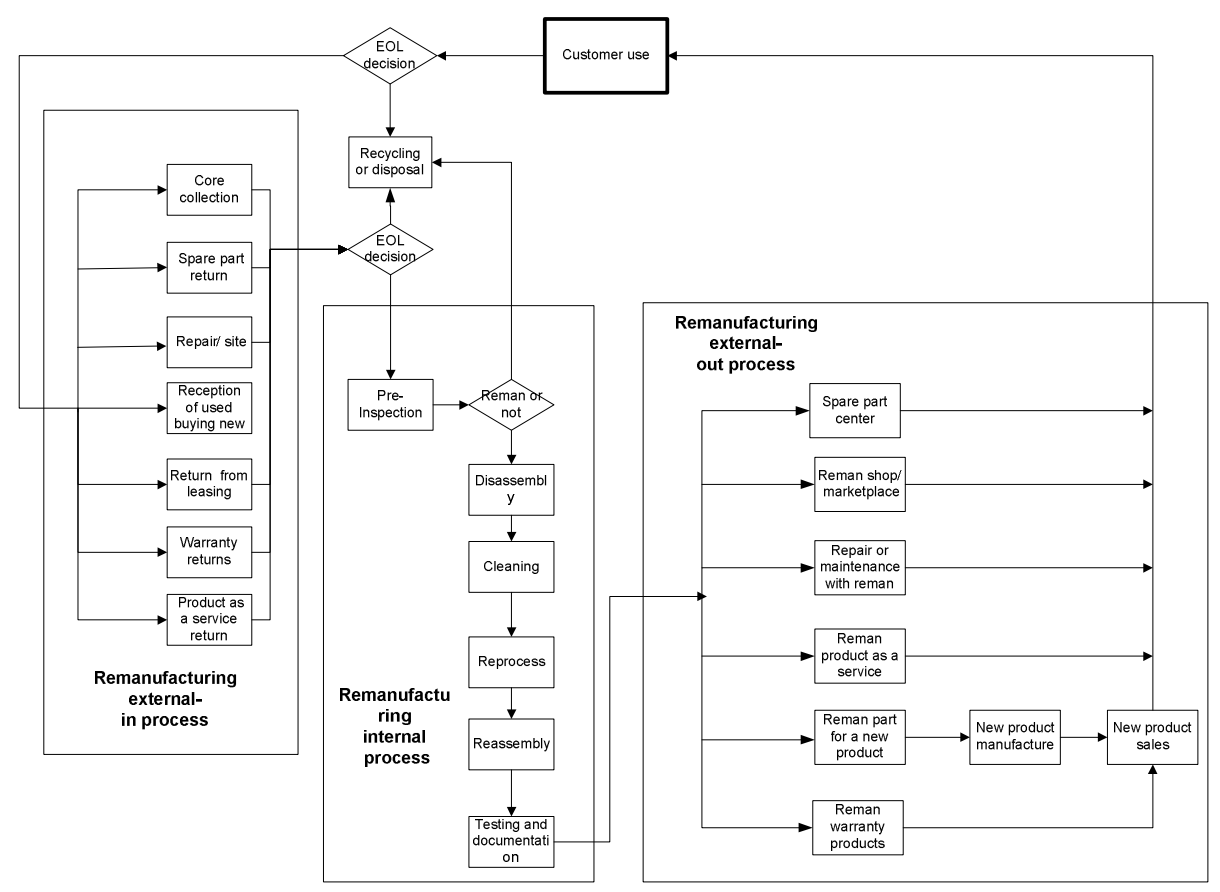

Fig. 1. Remanufacturing processes

\subsection{Actors and Roles in Remanufacturing}

In previous research, three main categories of remanufacturing are identified $[15,16$, 17], according to which partner takes care of remanufacturing:

1) the OEM (Original Equipment Manufacturer) itself,

2) contracted remanufacturers; "official" contractors / agents, and

3 ) independent or $3^{\text {rd }}$ party operators.

This classification mainly focuses on the internal remanufacturing process - taking into account the external processes brings out additional roles and actors. There are important tasks to be performed also in the external processes, in the collection of cores and the distribution of remanufactured products. These tasks offer potential for additional roles and services as the company performing the real remanufacturing is not always able or the best option to take care of the logistics.

The involved case companies already active in remanufacturing all followed mainly the OEM approach: they had the control of the whole remanufacturing process even if they could use the original suppliers of the components also for the remanufacturing. 
The other ones interested in remanufacturing could as well select the contracted remanufacturing option or operate themselves as $3^{\text {rd }}$ party actors in the remanufacturing process.

\subsection{Enterprise Networking in Remanufacturing}

To succeed in remanufacturing business, the companies need to achieve sufficient volume and cost-efficiency, flexibility and quality. These requirements are often drivers for inter-enterprise collaboration in industry [18]. Could collaborative networks -approach and the developments in the field [19, 20] support also companies as they are striving to set up remanufacturing?

In collaboration networks -research [18, 19] two main enterprise networking concepts are distinguished, based on the objective and the duration of the collaboration. The Collaboration network or Breeding environment -concept refers to long-term co-operation and creation of preparedness between the enterprises while virtual organisations or Virtual enterprises (VE) are temporal and focused on achieving a specific task. After fulfilling the task a VE is dissolved. Using these concepts in the remanufacturing context the collaboration network creates the preparedness for collaborative remanufacturing while the remanufacturing itself could be performed by a Virtual remanufacturing enterprise. When talking about what happens inside the factory walls as well a term "virtual factory" could be used. From the outside world the Virtual Remanufacturing Enterprise behaves and acts as a single company, but internally it consists of several partner organisations. Examples of companies that together could perform the process are cleaning, reprocessing, painting, coting, testing and logistics companies. The participation partner can be replaced over time. The Virtual Remanufacturing Enterprise could be created from the remanufacturing network for a specific product or component. Depending on the product type its duration could extend over the product generation lifetime or be even focused on one large product with low market share and volume.

Collaboration between different actors may be needed both in internal and external processes. Through the analysis of the project cases and their potential forms in the future three different network types were tentatively identified:

- OEM centric remanufacturing network: managed by the OEM but may include contracted remanufacturers,

-Industry-specific remanufacturing network: managed by a contracted remanufacturer or an independent actor,

- Location-based remanufacturing network / "Remanufacturing park": mainly independent actors but may also have contracts with OEMs.

In future, also remanufacturing ecosystems could emerge, extending over the different types and allowing collaboration and enriching across different industrial fields.

As mentioned above, the case companies already active in remanufacturing follow the OEM approach in remanufacturing. Analysis of their processes, however, shows, that the one having most wide remanufacturing activities is not performing the whole remanufacturing process alone, but has collaboration partners both in the internal and the external processes. Here the partners in the remanufacturing network are a subpart 
of the network of new product manufacturing: most of them also participate in the logistics, manufacturing or maintenance activities of new products. Only few specific centres for remanufacturing have been created. This kind of remanufacturing network could be called "OEM-centric remanufacturing network": it is managed and controlled by the OEM. In this way the OEM can take care of its brand, keep the customer relationship and ensure the quality of the remanufactured products or components.

The two other case companies already active do not have a corresponding network created but they also do not have as high volumes. However, while increasing the volume they could also benefit about creating collaboration in external or / and internal processes.

One of the case companies experienced difficulties to set up remanufacturing activities outside its main market area, because of too low market share and volume. In this case manufacturers of similar or near-by products could create common reverse logistics and/ or remanufacturing to reach the sufficient volume. One option is to collaborate only in the core collection and to perform the remanufacturing itself, another to share resources also in internal remanufacturing. This kind of networks could be called "Industry-specific remanufacturing networks". Even if this option might look attractive, many companies consider it impossible because of competition, fear of losing brand or market position. However, there are examples of collaboration also between competitors. In some cases the collaboration only involves the collection of cores, like used ink cartridges in Japan [5].

One of the SME case companies manufactures heavy machines and had identified the need for collaboration in remanufacturing and reuse of old products. The company is looking for partners in Central Europe to start the activity. In case of heavy products and low volume the sufficient volume could be achieved through collaboration in the same geographical areas. These networks could be called "Location-based networks". Sometimes also specific sites or "Remanufacturing parks" are created which may be operated by one or many partners, to remanufacture a wide range of products. In this collaboration, with high enough volumes, some partners could specialize on a definite remanufacturing process phase (disassembly, cleaning etc.) which could support the cost-efficiency. By extending and distributing the activities into several locations and fields the Remanufacturing park -idea could become a "Remanufacturing ecosystem".

Thus, it can be observed that as there is a large variety of products, there is also a large variety of potential collaborative networks in remanufacturing. It is not the same to remanufacture a high volume of low value components as low volume of high value products. The collaboration may support overcoming some of the challenges: for example the challenge of core collection, achieving sufficient volume and also balancing the supply and demand. It may also contribute to the accumulation of knowledge and experience regarding remanufacturing.

\section{Conclusions and Way Forward}

Remanufacturing can be seen as an ultimate form of recycling. Through remanufacturing, materials and energy can be saved and less waste is produced. At its 
best, a win-win-win situation is reached: the manufacturer can get additional income and profitable business, the customers get products with a lower price and with a quality guarantee, and the natural resources are used less. It should be noted that in addition to saving product value remanufacturing is already now but increasingly in the future able to add value to the remanufactured products. This is already done for example in engine or vehicle remanufacturing through improving energy efficiency and cutting emissions of engines.

Also benefits at the level of society are seen as remanufacturing can provide industrial employment in skilled jobs and may create new opportunities supporting the product lifecycle and its extension. As part of circular economy [2], remanufacturing can support sustainable re-industrialization.

To progress in circular economy, actions on several levels are needed. These may include governmental and legal actions, like environmental standards, waste penalties and incentives from taxation. At the company level barriers and challenges need to be solved. As a whole, the awareness and knowledge about remanufacturing needs to be built and disseminated. However, it is important to understand that going to circular needs systemic changes in product design, customer attitudes, business models and value networks. These will be further studied in the Finnish national DemaNET project.

Acknowledgement. This work has been partly funded by the Finnish Funding Agency for Technology and Innovation (Tekes) Green Growth program.

\section{References}

1. Biller, S.: Innovation in Global Manufacturing: Sustainability for Business Success. In: World Manufacturing Forum 2011, May 16-17, Como Lake (2011)

2. Ellen MacArthur Foundation: Towards a circular economy. Economic and business rationale for an accelerated transition. 98pages (2012)

3. Steinhilper, R.: Remanufacturing - The Ultimate Form of Recycling. Fraunhofer IPB Verlag, D-70569 Stuttgart. p. 108 (1998) ISBN 3-8167-5216-0

4. Lund \& Hauser: Remanufacturing - An American perspective. In: 5th International Conference on Responsive Manufacturing - Green Manufacturing (ICRM 2010), Ningbo, China, January 11-13 (2010) ISBN: 978-1-84919-199-9

5. Matsumoto, M., Umeda, Y.: An analysis of remanufacturing practices in Japan. Journal of Remanufacturing 1(2), 11 (2011)

6. Bücker, C.: A SME View to the remanufacturing Business-trends, Challenges \& Critical Impacts. In: Reman Summit 2012, Bayreuth, September 03-04 (2012)

7. Tekes: Tekes web site, http: / /www.tekes.fi (accessed March 12, 2013)

8. IMS2020: Roadmap on Sustainable Manufacturing, Energy Efficient Manufacturing and Key Technologies (February 15, 2010), http: / / www. ims2 020 . net Viewed August 2011

9. Lundmark, P., Sundin, E., Björkman, M.: Industrial Challenges within the Remanufacturing System. In: Proceedings of Swedish Production Symposium 2009, Stockholm, Sweden, pp. 132-138 (2009)

10. Östlin, J.: On Remanufacturing Systems - Analysing and Managing Material Flows and Remanufacturing Processes, Linköping Studies in Science and Technology, Thesis No. 1192 Department of Mechanical Engineering, Linköping University, SE-581 83 Linköping, Sweden (2008) 
11. Bennekrouf, M., Mtalaa, W., Boudhari, F., Sari, Z.: A Generic Model for network design including remanufacturing activities. In: International Workshop on Green Supply Chain, GSC 2012, Arras, France, June 21-22 (2012)

12. Sundin, E.: Product and Process Design for Successful Remanufacturing. In: Production Systems, Dissertation No. 906, Department of Mechanical Engineering. Linköping University, Linköping (2004)

13. Hauser \& Lund: Remanufacturing - An American Resource, http : / / www . bu . edu/reman/RemanSlides . pdf (accessed January 11, 2012)

14. Hatcher, G.D., Ijomah, W.L., Windmill, J.F.C.: Design for Remanufacture: a Literature Review and Future Research Needs. Journal of Cleaner Production 19(17-18), 2004-2014 (2011) ISSN 0959-6526

15. Lund, R.: Remanufacturing: The Experience of the United States and Implications for Developing Countries. World Bank, Washington DC (1984)

16. Parker, D., Butler, P.: An Introduction to remanufacturing. Centre of Remanufacturing and Reuse, 66773 UK, 15 p. (2007), http: / /www.remanufacturing.org.uk/pdf / reman_primer.pdf (accessed April 18, 2012)

17. Sundin, E., Östlin, J., Rönnbäck, A.Ö., Lindahl, M., Sandström, G.Ö.: Remanufacturing of Products used in Product Service System Offerings. Manufacturing Systems and Technologies for the New Frontier, 537-542 (2008) ISBN 1848002661

18. Kürümlüoglu, M., Nostdal, R., Karvonen, I.: Base concepts. In: Camarinha-Matos, L., Afsarmanesh, H., Ollus, M. (eds.) Virtual Organizations. Systems and Practices. Springer (2005)

19. Camarinha-Matos, L.M., Afsarmanesh, H., Ollus, M.: Methods and Tools for Collaborative Networked Organizations. Springer, New York (2008) ISBN 978-0-38779423-5

20. Romero, D., Molina, A.: Green Virtual Enterprise Breeding Environments: A Sustainable Industrial Development Model for a Circular Economy. In: Camarinha-Matos, L.M., Xu, L., Afsarmanesh, H. (eds.) PRO-VE 2012. IFIP AICT, vol. 380, pp. 427-436. Springer, Heidelberg (2012) 